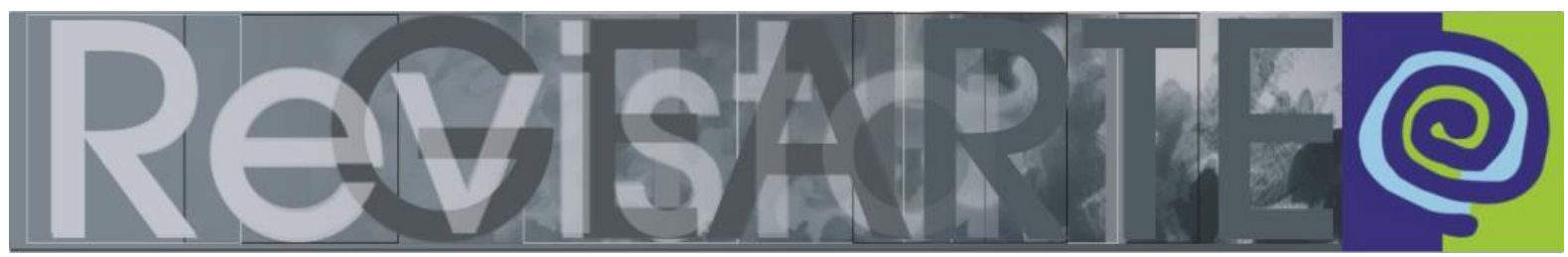

e-ISSN 2357-9854

\title{
GEARTE: uma experiência de transformação
}

\author{
Sandra Regina Simonis Richter \\ (Universidade de Santa Cruz do Sul — UNISC, Santa Cruz do Sul/RS, Brasil)
}

RESUMO - GEARTE: uma experiência de transformação - O ensaio apresenta um exercício de escrita em torno da experiência de pesquisar como transformação existencial ao compartilhar uma experiência formativa como professora de artes plásticas e pesquisadora no campo educacional das artes e das infâncias, a partir do estudo da dimensão poética da linguagem desencadeado nos anos 90 no Grupo de Pesquisa Educação e Arte - GEARTE.

PALAVRAS-CHAVE

Educação e arte. Dimensão poética. Pesquisa em Ciências Humanas. GEARTE.

RESUMEN - GEARTE: una experiencia de transformación - El ensayo presenta un ejercicio de escritura en torno a la experiencia de investigar cómo transformación existencial al compartir una experiencia de formación en cuanto profesora de artes plásticas e investigadora en el campo educativo de las artes y de las infancias, a partir del estudio de la dimensión poética del lenguaje desencadenado en los años 90 en el Grupo de Investigación Educación y Arte - GEARTE.

PALABRAS CLAVE

Educación y arte. Dimensión poética. Investigación en Ciencias Humanas. GEARTE.

Este ensaio emerge de uma escrita intencionalmente produzida para ser lida como comunicação no evento "GEARTE 21 anos: Diálogos entre Educação e Arte", ocorrido em agosto de 2018 no auditório da Faculdade de Arquitetura da Universidade Federal do Rio Grande do Sul. Nessa intenção, a escrita sustenta a afirmação de Jorge Ramos do Ó (RAMOS DO Ó; COSTA, 2007, p. 111) de que "todos escrevem a partir de rastros e de fragmentos de outras escritas". Portanto, o que apresento ao leitor é um exercício de recomposição de escrita outras, de uma reescrita pautada na errância do já escrito, para reafirmar que todo e qualquer exercício escritural é sempre uma reescrita de nós conquistada da opacidade do que tem que ser dotado de sentido, reformulado - ou narrado - para ser compreendido.

Não se trata de compreender como "pesquisa sobre educação e arte" que revela ou oferece conhecimentos sobre o presente, mas como desejo ou experiência de pensamento - como um esforço de retificação de mim mesma, como convite a pensar em direção ao tempo presente a mim, como ele aparece para mim a partir dos outros com quem converso e convivo. Tal esforço supõe assumir os paradoxos do 
vivido e "jogar-se na questão. A questão é esse convite ao salto, que não se detém num resultado" (BLANCHOT, 2001, p. 41; 53). Não se detém porque um resultado seria a desgraça da questão já que a relevância está no desejo do pensamento.

É o desejo do pensamento que me faz grata por participar deste evento. É com orgulho que dele participo e felicito a iniciativa de celebrar os 21 anos do GEARTE em tenso momento histórico nas políticas nacionais de educação e de pesquisa nos programas de pós-graduação no país. Um encontro muito bem-vindo tanto por celebrar uma história de professores e pesquisadores em Educação e Arte no Rio Grande do Sul quanto pelo oportuno momento de pararmos e conversarmos sobre o que estamos pensando e estudando em nossos grupos de pesquisa a partir de uma história comum em seus começos.

No que me diz respeito, o desafio de compartilhar a experiência de conviver no GEARTE em seus primeiros 10 anos implicou parar para pensar a singularidade de participar da criação de um grupo de estudos em Artes na pós-graduação em Educação a partir de uma história de professora de artes com crianças iniciada nos anos 70, na Escolinha de Arte da Associação dos Ex-Alunos do Instituto de Artes da Universidade Federal do Rio Grande do Sul/UFRGS. Uma suspensão no tempo que exigiu considerar a vitalidade dos começos e as transformações promovidas na minha existência como professora e pesquisadora. Essa vitalidade dos meus começos não aponta para a progressão de saberes, mas à sua variação - não se explica nem se dá a entender como conhecimento, antes emerge como disponibilidade a saborear a possibilidade de pesquisar-me ao pesquisar em Ciências Humanas. Implicou transgredir expectativas por respostas e soluções para assumir o risco da escrita como ação do e no presente.

Assim, opto por iniciar pelas interrogações que atualmente venho formulando e discutindo nos grupos de pesquisa Estudos Poéticos: Educação e Linguagem da Universidade de Santa Cruz do Sul/UNISC, o qual participo desde sua criação em 1999 e do qual atualmente sou líder, e no grupo PEABIRU: Educação Ameríndia e Interculturalidade da UFRGS e UNISC, uma experiência de pesquisa que vem 
redimensionando, desde 2013, minhas possibilidades de pensar a relação entre educação, artes e infâncias.

A experiência do encontro intercultural com os Guarani em suas aldeias e na universidade - a partir do projeto de pesquisa "Infâncias e Educação Guarani", coordenado pela professora Ana Luisa Teixeira de Menezes junto ao programa de pós-graduação em Educação da UNISC ${ }^{1}$, promoveu o encontro com um não saber, uma infância do pensamento, portanto o encontro com minhas possibilidades de redimensionar modos de pensar e interrogar processos educacionais com crianças e adultos. O que encontrei nas aldeias Guarani foi outro modo de pensar a experiência existencial da língua e modos de estar e conviver em linguagem (MENEZES; RICHTER, 2014; MENEZES; RICHTER; SILVEIRA, 2015; MENEZES; RICHTER; PINHO, 2018).

O encontro entre a cosmologia Guarani e os estudos da relação entre educação, artes e infâncias vem permitindo afirmar valores educacionais sustentados em uma poética e uma ética dos tempos lentos, do corpo no mundo, do imagético multissensorial, da presença encarnada das palavras-alma, do poder das narrativas míticas que revelam os diversos modos de ser ameríndio. A aproximação aos valores educacionais dos Guarani, seus modos de educar desde o nascimento, vem configurando importante estudo em torno da ancestralidade do pensamento ameríndio. Cabe destacar que a "essência" de algo como "ameríndio" é tão discutível como a existência mesma da América Latina como processo histórico e social único e homogêneo. Implica enfrentar debates complexos, profundos e com longa tradição e, aqui, a intenção é destacar a existência do termo "ameríndio" em contraposição ao europeu e ao norte-americano, ou seja, ao "ocidental".

Desde a interlocução entre meus estudos em torno da dimensão ficcional da linguagem na educação das crianças (RICHTER, 2004; 2005) e os estudos da dança

\footnotetext{
Edital FAPERGS 2013-2015 com o projeto "Infâncias e Educação Guarani" nas aldeias de Estrela Velha e do Salto do Jacuí (RS) e Edital Universal CNPq 2016- 2018 com o projeto "Aprendizagens interculturais com os Guarani: produção de conhecimentos ameríndios para a educação das infâncias" nas aldeias de Itapuã e Tekoá Pindó Mirim (RS).
} 
Guarani realizados por Ana Luisa Teixeira de Menezes (2006; 2010), a ludicidade da linguagem captura nosso interesse de pensar e compreender a educação das crianças como iniciação à presença da palavra que nos situa no mundo e que, na linguagem Guarani, torna-se palavra sagrada que os enraíza no mundo (MENEZES; RICHTER, 2014). Com Meschonnic (2001, p. 295), compartilhamos que as palavras não são destinadas a descrever as coisas, mas sim para nos situar entre as coisas. $\mathrm{Se}$ as concebemos como nomeação apenas mostramos a ideia mais pobre de linguagem. Por isso, para o autor, o poético emerge cada vez que "uma forma de vida transforma uma forma de linguagem e se reciprocamente uma forma de linguagem transforma uma forma de vida" (MESCHONNIC, 2001, p. 292).

O ponto de intersecção entre nossos estudos encontra-se em concebermos que o tema educacional dos processos iniciais de adentrar na linguagem e suas relações com distintos modos de conviver "implica também estar disponível para lidar com os materiais do sonho" (COUTO, 2011, p. 24), em lidar, simultaneamente, com as ordens do visível e do invisível. O grande desafio educacional está em resistir à tendência contemporânea de simplificação progressiva da existência pela simplificação dos processos de interagir e aprender a estar em linguagem no mundo comum. Talvez, nossa tarefa educacional esteja no ato de resistência ao desencantamento que vivemos diante da crescente aridez utópica que assola a convivência. Sonhar é hoje anacrônico.

O crescente realismo que tece discursos e narrativas contemporâneos promove a intensificação da separação entre as coisas das artes e a vida mundana ao delegar à objetividade a autoridade sobre o real - o realismo do mundo tangível - e relegar as artes ao mundo intangível do imaginário e da imaginação. Realismo é uma palavra chave do projeto neoliberal, que se quer objetivo, prático e aberto, isento de pretensões totalitárias e de ingenuidades utópicas (UNGER, 2001, p. 177). Um desencanto pelo mundo que coloca em questão a própria ideia de realidade como aderência ao pré-visto, ao já sabido, portanto ao que é passível de cálculo e planejamento prévio dos resultados. Por isso, Bárcena (2012, p. 37) destaca as palavras de Robert Musil, da obra inacabada O homem sem qualidades (1930), para RICHTER, Sandra Regina Simonis. GEARTE: uma experiência de transformação. 
afirmar que "temos conquistado a realidade e perdido o sonho". Já ninguém mais tateia o mundo, ninguém sonda a obscuridade do material informe da linguagem, todo mundo trabalha. Porém, como disse Habermas (1987, p. 114), "quando secam os oásis utópicos, estende-se um deserto de banalidades e perplexidades".

O que mobiliza atualmente meus estudos é a condição mágica da linguagem, aquela que não apenas nomeia, mas que inventa e produz encantamento. A linguagem comunica, mas não apenas serve para comunicar. Às vezes a linguagem nos faz ser e faz também não ser. A linguagem escapa à norma e aos códigos. Sonhar é resistir. Sonhar produz efeitos no real. É ato político.

Para enfrentar a magnitude política do fenômeno de começar-se em linguagem na coexistência mundana venho compondo nos últimos anos um "pensamento educacional" a partir da aproximação entre artes e infância voltado para o enigma do movimento de tornar-se operador fabuloso da e na linguagem. Aproximação traçada pela interlocução entre educação, poesia e filosofia para expor a experiência de linguagem como o elo que as reúne. O interesse intelectual é estudar a ação (po)ética de educar a partir do encontro com a filosofia como experiência de pensamento pautada na coexistência com outros no mundo.

Assim, tomo a filosofia como educação - ou educação como filosofia - e não como disciplina acadêmica, antes como um modo de indisciplina acadêmica que assume a dimensão poética da linguagem como possibilidade de ensaiar, como um exercício de pensamento que permita ressignificar palavras para reafirmar que "nenhuma dimensão da linguagem existe independente da ação do corpo que a inscreve no mundo e the confere sentido na convivência" (RICHTER; BERLE, 2015, p. 1029).

O interesse acadêmico é reivindicar ao pensamento pedagógico maior consideração pela potência lúdica do corpo aprender a começar-se em linguagem na íntima relação entre provocações à imaginação e desafios à razão. Um convite a não esquecer que desafiar o raciocínio (razão) não significa abandonar as 
provocações à fabulação (imaginação). Tanto as ciências quanto as artes, tanto a objetividade racional quanto a ambiguidade da imaginação poética, tanto a reflexão quanto o devaneio exigem leitura e produção de sentidos, exigem linguagem. Ou seja, exigem ensaiar um exercício de pensamento como tentativa de ressignificar palavras e verbos que possam começar de novo a falar de algo que nos coloque em movimento de pensar o encontro vital - sempre educacional - entre gerações como ato responsável de professar encantamentos - professar a alegria de pensar para expandir modos de agir no mundo e não cristalizá-los. Ato que supõe certo apetite pelo mundo, certo tipo de movimento que diz respeito a estar à altura da experiência mundana que fazemos e que nos é transmitida, as quais permitam sustentar a relevância de favorecer aos novos que chegam experiências lúdicas - brincantes - com e na linguagem.

Ser brincante da e na linguagem provoca rupturas nas convenções de linguagem para religá-las novamente ao pathos inerente ao fundo corporal, como sentido estésico da linguagem em sua sensualidade ambígua de "fazer sentido" - ao entrelaçar paixões na coexistência mundana. Nessa compreensão, ser brincante implica uma experiência de linguagem exigente e interpeladora, pois somente quando nos deixamos abrir a novos gestos de linguagem - rupturas e religações - podemos levar adiante o devir de nós mesmos (RICHTER, 2016a; 2017).

Essa abertura aos gestos de linguagem implica considerar que cada uma, poesia e ciência, faz a dificuldade da outra. "Juntas, elas são a própria dificuldade: de fazer sentido" (NANCY, 2013, p. 417). Fazer que não supõe a condição de revelar um sentido, mas de ex-por uma irrupção imprevista, inaugurar uma configuração ou outra compreensão. A condição do sentido é não ter sentido prévio. O real contém e conduz a absoluta indeterminação do mundo. Há muitos modos de realizá-lo. Como já afirmou Merleau-Ponty (1999, p. 440), a experiência do mundo "a cada instante se faz em nós", já que o mundo "não é aquilo que eu penso, mas aquilo que eu vivo; eu estou aberto ao mundo, comunico-me indubitavelmente com ele, mas não o possuo, ele é 
inesgotável" (MERLEAU-PONTY, 1999, p. 14). Nessa condição, a dimensão poética da linguagem é uma advertência aos limites da linguagem conceitual das ciências.

"E se fizéssemos ....?"

"E se ..." é seguido de um verbo no imperfeito. Jamais um tempo foi tão bem nomeado: o imperfeito se abre à perfectibilidade, ele é isto que não está acabado e é frequentemente seguido, conforme consagrado, por outro verbo no condicional: "poderíamos". Sim, mas na condição de ... tocar o mundo. Tocar o mundo significa existir, "sair do modo de ser em subsistência", pelo modo humano - ou gesto técnico - de implementar "um poder ser" (RIBAULT, 2011, p. 2). O pacto original entre corpo e mundo que o gesto evidencia, é a condição de partida do agir técnico, o qual permite ao humano constituir um mundo possível (GALIMBERTI, 2006, p. 87). O gesto, como resposta do corpo ao mundo que o interpela, por emergir da ação de tocar e ser tocado pelo mundo, é movimento de produção e circulação de sentido.

Aqui, abordo o fenômeno das artes como ação entre humanos que expõe ações humanas. Nesse sentido, sublinho o termo artes no plural, pois considero literatura, música, dança, fotografia, artes plásticas, cinema, teatro, distintos nomes dados à produção poética de sentidos. Considero, com Nancy (2014), que o princípio heterogêneo da singularidade plural das artes é a sensualidade como sentir sentido e sentir que se sente a partir da complexa relação que mantêm entre si os dois sentidos do sentido: sentido sensato ou inteligível e sentido sensível, na qual não há subordinação de um pelo outro. Antes, multiplicam em nós sentidos. Essa capacidade é inerente à condição humana de sermos contadores de histórias, produtores de linguagem e cantadores de esperanças, guardadores de memórias e crenças que não nos deixam esquecer que o poder criador e inventivo do humano está em sermos capazes de valorar a existência para compartilhá-la (RICHTER, 2016b). Valorar a existência depende de uma linguagem que contemple as qualidades da vida.

A atenção estésica para as qualidades da vida, seus detalhes e mistérios, diz respeito à potência poética da imaginação animar a linguagem e forjar brechas para 
a ânima das coisas mundanas ao conferir-lhes existência pela intimidade da experiência que o corpo faz delas e dele mesmo. A experiência poética supõe um determinado gesto que se ex-põe e se mostra para além da comunicação ao nos oferecer uma analogia da existência: um risco aberto, sem objeto. Poética e existência são fenômenos solidários em seus respectivos movimentos constitutivos do humano: expor-se e manter-se. Aqui, a imaginação poética faz emergir a linguagem como amálgama da vida compartilhada.

Tal compreensão de imaginação poética implica assumir que o fenômeno da linguagem não é meio ou instrumento de entendimento de nós ou de mundo, mas a condição existencial absoluta para que tenhamos mundo. Aqui, a imaginação - a ação de imaginar - não é dinâmica desordenada, vestígio fantasmal da percepção visual, pelo contrário, é dinâmica projetiva que encontra toda sua força ou energia transfigurativa ao colocar o corpo em linguagem e transfigurar a realidade para engendrar narrativas e plasmar ações na convivência mundana (RICHTER, 2005).

Resistir ao processo de desertificação utópica que nos assola é dispor-se a adentrar uma infância do pensamento para interrogar e recomeçar: "E se pudéssemos fazer isto ou aquilo com isto ou aquilo..."? «E se ...» dizem as crianças, que não fazem nada mais que jogar e brincar para explorar o mundo das possibilidades. "Paradoxo: o que resiste é que há brincadeira" (NANCY, 2016, p. 184). O que resiste é que há infâncias....

O problema está em sustentar que é aos adultos - docentes ou não - que cabe a tarefa lúdica de aprenderem a imaginar para poderem provocar e desafiar o raciocínio brincante das crianças e dos jovens. Sempre são os outros que nos alcançam a linguagem. Como afirma Certeau (2012, p. 143), cultura "consiste não em receber, mas em exercer a ação pela qual uma marca aquilo que outros lhe dão para viver e pensar". Considerar o que os outros nos oferecem para tecer a historicidade de um percurso existencial é considerar o que determinada época faz com a gente, o que a convivência com outros de uma época me permite pensar e falar, o que me faz falar o que falo, o que escrevo, o que canto, o que pinto. 
Foi por vontade de encontrar-me semanalmente com alguns outros que me forçavam pensar o que não sabia ser capaz que intempestivamente acolhi o convite de Elton Manganelli para vir semanalmente a Porto Alegre frequentar uma disciplina do programa de pós-graduação em educação da UFRGS com a professora Analice Dutra Pillar, ex-colega nossa no Instituto de Artes da UFRGS. Na época, não alcançava o significado futuro disso. Queria apenas estar com aqueles aos quais sentia saudades de conversar, de discutir ideias e compartilhar experiências em educação e arte com bebês, crianças, jovens e adultos. Era o primeiro curso que a Analice oferecia no Programa de Pós-graduação em Educação da UFRGS, após a conclusão do seu doutorado na USP com a professora Ana Mae Barbosa.

No segundo semestre de 1995, fiz outra disciplina, "Arte e conhecimento", e foi então que a Analice me incitou a participar da seleção para o mestrado em educação. Entrei na pós-graduação em Educação da UFRGS e minha dissertação, sob sua orientação, deteve-se no encontro entre criança e pintura. Após esses anos, entendo o mergulho apaixonado no estudo da cor e a investigação em torno dos processos pictóricos das crianças como um regate de minha história no Instituto de Artes e na Escolinha de Arte na UFRGS. O estudo em torno da relação entre imaginação poética e pintura emergiu como experiência de pensar a singularidade do meu processo poético com o gesto e a cor para uma aproximação fenomenológica à experiência pictórica com crianças. Apaixonei-me pela compreensão de que não se pinta com ideias, ou com os olhos, mas com a mão, o instrumento e a materialidade da cor!

A interlocução que estabeleci entre Gaston Bachelard, Jean Piaget e Johann Wolfgang von Goethe colocou-me diante do problema incontornável da relação entre imagem e palavra. Relação que se tornou bastante incomoda pois conclui a dissertação afirmando a separação entre verbal e não verbal. Ao final da banca de defesa da dissertação instalou-se a grande constatação em mim: manter a distância entre palavra e imagem nada mais era que manter a redutora polarização entre mente e corpo, entre pensar e fazer! 
Após a conclusão do mestrado, desencadeamos no grupo de Estudos Poéticos: Educação e Linguagem da UNISC três anos de estudos em torno de nosso primeiro projeto de pesquisa: $A$ poética do devaneio e da imaginação criadora na obra de Gaston Bachelard. Nesse mesmo ano, iniciei o doutorado com a Analice na intenção de estudar argumentos para defender que arte não é "atividade", mas um fazer que é um pensar em ato, um pensamento encarnado que emerge do corpo sensível operante em seu poder de iniciar ações no mundo e dar outro rumo às coisas.

Iniciei o doutorado para continuar interrogando a relação entre imaginação poética, educação e infâncias. Preparei a qualificação do projeto de tese focalizando a relação entre educação, artes plásticas e infância a partir do conhecimento sensível ou pensamento imagético. Porém, percebi que estava, mais uma vez, polarizando aquilo que justamente considerava inseparável: a dimensão sensível da inteligível.

Após 18 meses, convivendo semanalmente com cento e trinta crianças de zero a seis anos e suas professoras, as crianças me mostraram que o insubstituível da experiência brincante com as materialidades e instrumentos artísticos na educação não é tanto a dimensão artística e nem a dimensão estética, mas a antiga e esquecida dimensão poética que advém do encantamento de um corpo - de uma alegria fascinada - diante das primeiras admirações com a plasticidade do mundo que convocam o corpo das crianças a "mexer-se" e lançar-se ludicamente para encená-lo porque pode ficcionar a experiência de partilhar o mundo, em seus jogos e brincadeiras, como modo de aprender a decifrá-lo e interpretá-lo.

Foi necessário, então, afastar-me da tradição dos estudos que aproximam arte, educação e infância, para alcançar a lacuna na discussão em torno da dimensão educativa das artes na infância. Foi teórico-metodologicamente necessário porque, nas pesquisas educacionais, o ficcional, como dimensão que torna inteligível o real, não constitui interrogação pedagógica para pensar o ato lúdico e lúcido de narrar o vivido. Pelo contrário, a concepção de criança naturalmente criadora, só por ser criança, dotada de imaginação livre e desenfreada, liberta das amarras do corpo, é a garantia do acontecimento "criador" na escola. 
Assim, apenas de outro lugar, no qual a questão da imaginação poética aparecesse como questão para o pensamento e o conhecimento, foi possível escutar o silêncio em torno da relação entre dimensão ficcional e aprendizagem das linguagens plásticas e constatar a ausência da discussão sobre como a concebemos na educação de crianças. As fenomenologias da imaginação poética em Gaston Bachelard, do corpo sensível em Maurice Merleau-Ponty e da ação narrativa em Paul Ricoeur constituíram então importante chave filosófica para resistir aos estreitos marcos conceituais que fazem da educação o domínio de um realismo banal, sustentado na transmissão pré-vista de conhecimentos e no ensino analítico que elimina o misterioso e a admiração.

Nessa perspectiva, alcancei a violenta dinâmica do processo educacional com crianças como processo sustentado na vinculação do conhecimento à correção (em grego orthótes) do olhar a partir do "ver corretamente" ou na "orientação correta". Essa concepção ortogênica na educação com crianças pequenas exige o controle escolar do "desassossego", da inquietude que advém do movimento dos corpos no mundo, até a completa abstenção do movimento físico: olho fixo na palavra analítica do professor. A theoria - ou contemplação - corrige a escuta. Ao final, os estudos no doutorado verticalizaram em mim o poder da cor e do gesto de pintar, a potência mundana do pensamento pictórico.

Atualmente, junto ao grupo de Estudos Poéticos: Educação e Linguagem da UNISC, estou concluindo o projeto de pesquisa "Educação, arte e infância: mímesis e experiência de linguagem na educação da infância”. Uma pesquisa desencadeada em 2016 para estudar o fenômeno da mímesis como importante estratégia teóricometodológica para circunscrever um campo de pensamento em torno da ludicidade da linguagem a partir da potência mimética como poder ficcionante de tornar presente o que sem essa produção (poiésis) não poderia apresentar-se como tal. O fenômeno da mímesis emerge assim como a condição de possibilidade de saber das coisas, de um saber encarnado que pode fazer aparecer ou presentificar as coisas no mundo. 
A relevância científica para o grupo está em aproximar estudos em torno da relação entre mímesis e experiência lúdica de linguagem como produção poética de presença no mundo; como modo de contribuir com argumentos em torno da inseparabilidade entre corpo, linguagem e mundo que o grupo vem perseguindo nas suas pesquisas. Cada vez mais nos interessa a esquecida dimensão poética da linguagem, como dimensão produtiva de sentidos. Trata-se de lembrar à educação a inseparabilidade entre imaginação e razão - sensível e inteligível - no ato de aprender a conviver e participar do mundo. Inseparabilidade que acontece no tempo da ação do corpo no e com o mundo.

Assim, em meu processo de aprender a interrogar esse campo minado dos territórios educacionais para perseguir uma experiência de pensar outros modos ou outras políticas para o encontro entre educação, artes e infâncias, ando muito misturada em minhas tentativas de compreender a dimensão poética dos fazeres coletivos, na ciência e na arte. Minha admiração pela pintura, minha paixão pelo pictórico, favorece as misturas, as hibridizações, privilegia os lugares mestiços; procura o polimorfo, busca a polissemia das invisibilidades, se instala entre as luzes e as sombras, persegue o vigor do agir em linguagem, a poiésis que forja technes. Um fazer que me faz em meu saber fazer. Já disse Derdik (2010, p. 34), "arte não se sabe, se faz para saber" e fazer coisas exige ação do corpo sensível operante no mundo, isto é, exige ação realizante ou reificadora como condição de aprender a "entrar no reino poético para tornar-se sensível a sua coerência" (BACHELARD, 1990, p. 46). Assim, toda definição do fenômeno poético é, em si mesma, uma decisão redutora de sua potência de transfigurar o mundo. Decisão que não faz mais que provocar uma dissimulação da força vital do corpo linguageiro em movimento no mundo, uma redução pautada pela "demarcação fútil de fronteiras ali onde não deveria haver mais que uma violenta porosidade, mais que uma humana impossibilidade de contenção" (SKLIAR, 2005, p. 189).

Analice Pillar e o GEARTE me permitiram compreender que podemos ensinar os começos, nunca as transformações. Em meus começos, com a Analice e o grupo, compreendi - somente hoje posso alcançar - a relevância de uma orientação como 
acompanhamento pautado pela confiança no que poderá ser transformado ... agradeço imensamente a confiança em meus devaneios e possibilidades lúdicas e lúcidas que eu não sabia poder jogar... foi necessário aprender a escrever, mobilizar palavras em busca de outras palavras. Muito obrigada.

\section{Referências}

BACHELARD, G. Fragmentos de uma poética do fogo. Organização e notas Suzanne Bachelard. São Paulo: Brasiliense, 1990.

BÁRCENA, Fernando. El alma del lector. La educación como gesto literario. Bogotá D.C., Colombia, Babel Libros, 2012.

BLANCHOT, Maurice. A conversa infinita. São Paulo: Escuta, 2001.

CERTEAU, Michel de. A cultura no plural. Campinas, SP: Papirus, 2012.

COUTO, Mia. E se Obama fosse africano? e outras intervenções. São Paulo: Companhia das Letras, 2011.

DERDYK, Edith. Linha de costura. Belo Horizonte: C/Arte, 2010.

GALIMBERTI, Umberto. Psiche e Techne: o homem na idade da técnica. Tradução José Maria de Almeida. São Paulo: Paulus, 2006.

HABERMAS, Jürgen. A nova intransparência: a crise do Estado de bem-estar social e o esgotamento das energias utópicas. Novos Estudos CEBRAP, São Paulo, Centro Brasileiro de Análise e Planejamento, n. 18, p. 103-114, set. 1987.

MERLEAU-PONTY, Maurice. Fenomenologia da percepção. Tradução Carlos Alberto Ribeiro de Moura. São Paulo: Martins Fontes, 1999.

MENEZES, Ana Luisa Teixeira de. A alegria do corpo-espírito saudável: ritos de aprendizagem guarani. 2006. Tese (Doutorado em Educação) - PPGEdu/Universidade Federal do Rio Grande do Sul, Porto Alegre, RS.

MENEZES, Ana Luisa Teixeira de; RICHTER, Sandra R.S.; SILVEIRA, Viviane Fernandes. Nhandereko Kue Kyringüe'í Reko Rã. Nossa história para as crianças. Porto Alegre: Imprensa Livre, 2015.

MENEZES, Ana Luisa Teixeira de; RICHTER, Sandra R.S. Infância e educação guarani: para não esquecer a palavra. Tellus (UCDB), v. 26, p. 101-118, 2014.

MENEZES, Ana Luisa Teixeira de. Educação mito-dança-rito: as razões dialógicas do conhecer guarani. Currículo sem Fronteiras, 1, v. 10, 147-159, jan./jun. 2010.

MENEZES, Ana Luisa Teixeira de; RICHTER, Sandra R. S.; PINHO, Ana Maria de. Mito, Simbolismo, espiritualidade e vivência na Educação Guarani: contribuições para outro pensamento educacional. Educação, Sociedade \& Culturas, pp. 47 - 63, junho 2018, Porto, Edições Afrontamento/CIIE.

MESCHONNIC, Henri. Célébration de la poésie. Paris: Verdier, 2001.

NANCY, Jean-Luc. Demanda. Literatura e filosofia. Florianópolis: Ed. UFSC; Chapecó: Argos, 2016.

NANCY, Jean-Luc. El arte hoy. Ciudad Autónoma de Buenos Aires: Prometeo Libros, 2014.

NANCY, Jean-Luc. Fazer a poesia. ALEA: Rio de Janeiro. Jul-dez, vol. 15/2, p. 414-422, 2013.

RAMOS do Ó, Jorge; COSTA, Marisa Vorraber. Desafios à escola contemporânea: um diálogo. Educação \& Realidade, v. 32, n. 2, p. 109-116, jul. dez. 2007. 
RIBAULT, Patricia. Du toucher au geste technique : la «technè des corps». Appareil [En ligne]. Revue de la MSH Paris Nord (CNRS, Paris 8 \& Paris 13), 8, 2011, (sous la dir. de Ph. Roy): Le Geste. Disponível em: http://journals.openedition.org/appareil/1315 Acesso em 21 de abril 2018.

RICHTER, Sandra R. S. Jogar e brincar: potência do inútil. Revista Pátio Educação Infantil, v. 15, n. 50, jan./mar. 2017.

RICHTER, Sandra R.S. Educação, arte e infância: tensões filosóficas em torno do fenômeno poético. Revista Crítica Educativa, v. 2, n. 2, 2016a, p. 90-106, Dossiê: Infância e Educação Infantil: abordagens e práticas.

RICHTER, Sandra R.S. Docência e formação cultural. v. 2, p. 13-54. In: BRASIL. Coordenação Geral de Educação Infantil. BAPTISTA, M. C.; NEVES, V. F. A. (Org.); NUNES, M. F. R. (Org.); BARRETO, A. S. (Org.); CORSINO, P. (Org.); COELHO, Rita de Cássia Freitas (Org.). Leitura e escrita na Educação Infantil (10 volumes). 1. ed. Brasilia: MEC/SEB, 2016b. 10 v.

RICHTER, Sandra R.S; BERLE, S. Pedagogia como gesto poético de linguagem. Educação e Realidade, v. 40, p. 1027-1043, 2015.

RICHTER, Sandra R. S. A dimensão ficcional da arte na educação da infância. Tese (Doutorado em Educação) - PPGEdu/UFRGS, Porto Alegre, 2005.

RICHTER, Sandra R. S. Criança e pintura: ação e paixão do conhecer. Porto Alegre, RS: Mediação, 2004.

SKLIAR, C. De ausencias y, también, de presencias. In: LARROSA, Jorge; SKLIAR, Carlos (coord.). Entre pedagogía y literatura. Buenos Aires: Miño y Dávila, 2005, p. 187-199.

UNGER, Nancy Mangabeira. A desertificação do homem contemporâneo. Linhas Críticas, Brasília, v. 7, n. 13, jul/dez. 2001, p. 175-182.

\section{Sandra Regina Simonis Richter}

Graduada em Educação Artística, Habilitação Artes Plásticas, pela Universidade Federal do Rio Grande do Sul (UFRGS), com mestrado e doutorado em Educação pela Universidade Federal do Rio Grande do Sul. Pesquisadora e Professora Adjunta do Departamento de Educação, atuando na Graduação, na Extensão e no Programa de Pós-Graduação em Educação da Universidade de Santa Cruz do Sul. Atualmente é coordenadora adjunta do PPGEdu da UNISC, líder dos grupos de pesquisa Estudos Poéticos: Educação e Linguagem e LinCe - Linguagem, Cultura e Educação da UNISC e pesquisadora do grupo Peabiru: Educação Ameríndia e Interculturalidade.

E-mail: srichter@unisc.br

Currículo Lattes: http://lattes.cnpq.br/8984188058707610

Recebido em 12 de novembro de 2018 Aceito em 10 de fevereiro de 2019 